\title{
Effect of Thermo-mechanical Load Cycling on Microleakage in Class II Ormocer Restorations
}

\author{
Dina Erdilek ${ }^{a}$ \\ Can Dörter \\ Fatma Korayc \\ Karl-Heinz Kunzelmann ${ }^{d}$ \\ Begum Guray Efes ${ }^{b}$ \\ Yavuz Gomec ${ }^{\text {b }}$
}

\section{ABSTRACT}

Objectives: The objective of this in vitro study was to evaluate the marginal sealing ability of an ormocer in comparison with a hybrid composite when using thermocycling and load cycling procedures together in the study design.

Methods: Modified proximal Class II cavities were prepared on the mesial and distal surfaces of twenty-two human premolars. Each tooth was restored with Admira and contralaterally with TPH Spectrum. Half of all of the teeth were subjected to thermo-mechanical load cycling. After dye penetration, longitudinal sections in mesio-distal direction were prepared and examined under a stereomicroscope. Data were analyzed with Mann Whitney U test.

Results: The results showed that the thermo-mechanical load cycling caused a statistically significant increase in gingival microleakage when compared with the non-thermocycled and nonloaded restorations for both the materials Admira ( $P=0.006)$ and TPH Spectrum ( $P=0.023)$.

Conclusions: Simultaneous load cycling and thermocycling are decisive factors in the in vitro assessment of gingival microleakage, which still remains to be a clinical problem even with the ormocer system Admira. (Eur J Dent 2009;3:200-206)

Key words: Ormocer; Microleakage; Load cycling; Thermocycling.

\footnotetext{
a Dr, Department of Operative Dentistry, Faculty of Dentistry, Istanbul University, Istanbul,Turkey.

${ }^{b}$ Associate Professor, Department of Operative Dentistry, Faculty of Dentistry, Istanbul University, Istanbul, Turkey.

c Professor, Department of Operative Dentistry, Faculty of Dentistry, Istanbul University, Istanbul, Turkey.
}

d Professor, Department of Restorative Dentistry and Periodontology, Ludwig-MaximiliansUniversity, Munich, Germany.

- Corresponding author: Dr. Dina Erdilek Department of Operative Dentistry, Faculty of Dentistry, Istanbul University, Istanbul,Turkey. Phone : +90 $2124142020 / 30302$ Fax : +90 2125250075 E-mail : derdilekayahoo.com 


\section{INTRODUCTION}

The bond quality of the restorative material to the tooth substance is one of the factors that determine the longevity and clinical performance of dental restorations. Weakly bonded toothrestoration interfaces are more prone to the effects of the masticatory forces and oral thermal stress in the short and long term. Gap formations resulting in microleakage might occur readily. Oral fluids, molecules, ions and microorganisms may leak between the restorative material and the cavity walls. ${ }^{1}$ Microleakage may lead to problems such as postoperative sensitivity, marginal discoloration and breakdown at the tooth-restoration interface, recurrent caries and pathological changes of the pulp tissue..$^{2-5}$

Cavity type and design and the localization of the restoration may affect the microleakage pattern. An enamel bevel along the margins of the facial and lingual vertical walls of Class II cavities prepared for resin-based composite restorations has been shown to minimize the microleakage of the vertical and also the gingival margins. ${ }^{6}$

Today, the progress in adhesive dentistry has led to the improvement of the marginal integrity and consequently the clinical performance of dental restorations. However, microleakage still remains to be a clinical problem. Restorations with margins in gingival region and especially located below the cement-enamel junction exhibit still difficulties in achieving properly sealed restorative margins even with esthetic restorative materials using newly developed effective adhesive systems. ${ }^{7-13}$

Ormocers are organically modified ceramic materials which have been recently developed restorative systems and claimed by the manufacturer to have a high biocompatibility, a less polymerization shrinkage which is related to the size of the monomer molecules, a high adhesion to dentine and enamel and a proper marginal tight for all classes of cavities.

Several past studies investigated microleakage pattern using only thermocycling procedure in their materials and methods. To simulate oral masticatory forces however, load cycling procedure alone or together with thermocycling were also used in recent studies. The findings of all of these studies which evaluated different restorative systems with different cavity types revealed contradictory results on the role and effects of thermocycling and load cycling on micro-and nanoleakage. ${ }^{14-31}$

Rigsby et $\mathrm{al}^{27}$ found that the microleakage at the cementum aspects of composite resin restorations subjected to both temperature cycling and occlusal loading was significantly more than the ones subjected to only temperature or load cycling. Jang et $\mathrm{al}^{20}$ also showed that application of load cycling in conjunction with thermocycling significantly increased the microleakage.

The objective of this in vitro study was twofold: 1) To assess the marginal sealing ability of an ormocer compared with that of a hybrid composite in box-only Class II cavities, and 2) to evaluate the effect of thermocycling and load cycling applied together during the testing procedure on the pattern of microleakage.

\section{MATERIALS AND METHODS}

Twenty-two human premolars extracted due to orthodontic reasons were used in this study. They were free from caries and/or restorations and had no developmental defects. Proximal box-only Class II composite cavities with occlusal bevels of approximately $0.5 \mathrm{~mm}$ were prepared on the mesial and distal surfaces of each tooth. The gingiva walls which were located on enamel had a mesio-distal dimension of about $1 \mathrm{~mm}$ and a bucco-lingual dimensions of about $2 \mathrm{~mm}$. The depth of the preparations was determined according to the morphology of the teeth. All of the cavities were prepared using a diamond fissure bur (\# 835) with a diameter of $1 \mathrm{~mm}$ in a watercooled high-speed handpiece and the dimensions were confirmed with a vernier caliper (Tesa, Swiss). The preparations were also modified to include enamel bevels of approximately $0.5 \mathrm{~mm}$ on the vertical facial and lingual cavity margins using a diamond bur (\# 860).

Half of the cavities were restored with an ormocer material (Admira, Voco, Cuxhaven, Germany). The etchant (Vococid, Voco, Cuxhaven, Germanyl was applied to the enamel surface for $30 \mathrm{~s}$ and to the dentin surface for $15 \mathrm{~s}$ and then rinsed with water spray for 20 s and excess water removed with a light air stream so as to avoid desiccation. A layer of Admira Bond was applied and rubbed for 30 s and cured with halogen light (Astralis 3, Vivadent, Austria) for 20s. Then the 
cavities were restored with Admira with horizontal increments of $2 \mathrm{~mm}$ and cured for $40 \mathrm{~s}$.

The contralateral halves were restored with a hybrid composite (TPH Spectrum, Dentsply Caulk, Dentsply International Inc.. Milford, USA) (De Trey, Konstanz, Germany). The etchant (De Trey Conditioner 36) was applied to the enamel surface for 30 s and to the dentin surface for 15 s and then rinsed with water spray for $15 \mathrm{~s}$ and excess water was removed gently with air stream. Prime and Bond NT was applied and rubbed for $25 \mathrm{~s}$ and cured with halogen light (Astralis 3, Vivadent, Austrial for 15s. Cavities were restored with TPH Spectrum with increments of $2 \mathrm{~mm}$ and cured for 40s. All of the restorations were finished with a \# 23 carbide bur.

The teeth were stored in room temperature and distilled water for 1 week, then they were randomly assigned to one of the two experimental groups. The first experimental group was subjected to thermocycling and load cycling. The teeth of this group underwent 2000 thermal cycles between 5 and $55{ }^{\circ} \mathrm{C}$ with a dwell time of 30 s. During this procedure a force of $50 \mathrm{~N}$ was delivered with a total of 50000 cycles at $1 \mathrm{~Hz}$. The thermocycling and loading tests were performed in the tribology laboratory of Ludwig-Maximillians University in Munich. The second experimental group was not subjected to thermocycling and loading treatments.

The apices of all of the specimens were sealed with sticky wax and all tooth surfaces were covered with two coats of nail varnish to within approximately $1 \mathrm{~mm}$ of tooth-restoration margins. All specimens were then immersed in a $10 \%$ solution of methylene blue dye for $4 \mathrm{~h}$ at room temperature. Then they were rinsed and dried. After removed the nail varnish they were invested in clear resin. The teeth were sectioned longitudinally in mesio-distal direction with a low-speed water-cooled diamond saw (Isomed, Buehler Ltd, Lake Bluff, IL). ${ }^{22}$ sections of each test group were visually examined for dye penetration under a stereomicroscope (Baush and Lomb, Inc. NewYork USAl at X5 magnification.

Occlusal and gingival microleakage were scored according to these criteria:

Occlusal margin: $0=$ no dye penetration; $1=$ dye penetration extending less than or up to $1 / 2$ the distance to the dentin-enamel junction; $2=$ dye penetration greater than $1 / 2$ and up to but not past the dentin-enamel junction; $3=$ dye penetration past the dentin-enamel junction along the axial wall or up to the cavity depth; $4=$ dye penetration beyond the cavity depth in pulpal direction.

Gingival margin: $0=$ no dye penetration; $1=$ dye penetration that extended less than or up to $1 / 2$ of the gingival wall; $2=$ dye penetration greater than $1 / 2$ or up to $3 / 4$ of the gingival wall; $3=$ dye penetration greater than $3 / 4$ of the gingival wall or up to the junction of gingival and axial wall; $4=$ dye penetration beyond the junction of the gingival and axial wall in pulpal direction.

Data were analyzed with Mann Whitney U test. The significance level of the statistical analysis is 0.05 .

\section{RESULTS}

The distribution of the microleakage scores for both Admira and TPH Spectrum at the occlusal and gingival margins in non-thermocycled and non-loaded teeth are shown in Table 1 and Table 3.

In teeth which were not thermocycled and not loaded, the difference between the occlusal and gingival microleakage for Admira was statistically significant in favor of the occlusal scores $(z=2.39$, $P=0.017)$. But, the difference between the occlusal and gingival microleakage for TPH Spectrum was not statistically significant; the $p$ value was found to be very close to the significance level $(z=1.94$, $\mathrm{P}=0.053$ )

In non thermocycled and non loaded teeth, there was no statistically significant difference between Admira and TPH Spectrum for both the occlusal and gingival microleakage locclusal; $z=0.06, P=0.949$, gingival; $z=0.22, P=0.826$ ).

The distribution of the microleakage scores for both Admira and TPH Spectrum at the occlusal and gingival margins in thermocycled and loaded teeth are shown in Table 2 and 3. In teeth subjected to thermocycling and loading cycling, the gingival microleakage values of both restorations were significantly higher than the occlusal values (Admira; $z=4.46, P=0.0001$, TPH Spectrum; $z=3.45, P=0.001)$. In test conditions of thermocycling and load cycling, no statistically significant differences were found between Admira and TPH Spectrum for both the occlusal and gingival microleakage values locclusal; $z=0.38, P=0.97$, gingival; $z=0.356, P=0.722$ ). The 
statistical comparison of both of the experimental groups revealed no significant difference in the occlusal microleakage for both restorative materials (Admira; $z=0.48, P=0.63$, TPH Spectrum; $z=0.38, P=0.704)$. But the statistical comparison of both of the experimental groups revealed that the thermocycled and loaded restorations showed significantly more microleakage at gingival margins than the non-thermocycled and nonloaded ones in both restorative materials (Admira; $z=2.75, P=0.006$, TPH Spectrum $z=2.27, P=0.023$ ). The dye penetration at dentin of both restorations in non-thermocycled and non-loaded teeth is given in Figure 1 and the dye penetration at dentin after thermocycling and loading is given in Figure 2.

\section{DISCUSSION}

Box type Class II restorations were considered to be an appropriate design for this microleakage study, as longitudinal mesio-distal sectioning of the specimens allows us to evaluate both occlusal and gingival leakages simultaneously. Several previous studies demonstrated significantly more leakage in gingival margins than the occlusal margins for Class II composite restorations.8,9,12,13 Some studies indicated that the gingival margins of adhesive restorations which were located adjacent to or below the cemento-enamel junction

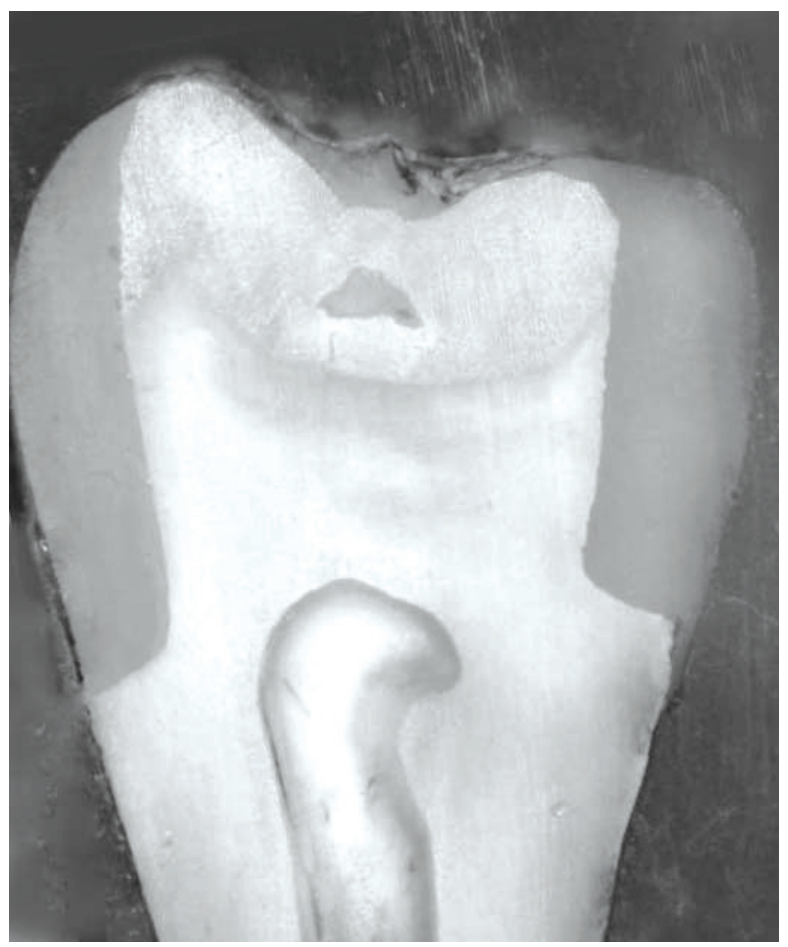

Figure 1. Dye penetration at dentin in non-thermocycled and non-loaded teeth. did not provide a good marginal adaptation of the restorative material and the low quality of the marginal seal led to an increase in gingival microleakage. ${ }^{10,12}$ The leakage was related to the inadequate bonding between the adhesive material and the tooth structure, such as a nondentinal layer or a cementum layer or a prismless enamel. However, the enamel margins of adhesive restorations in the gingival area still demonstrated significantly less microleakage than the cementum margins, although a prismless enamel layer was found $0.5 \mathrm{~mm}$ above the cementoenamel junction.7.12 In our experimental design, the box type Class II cavities were also prepared with gingival margins located about $0.5 \mathrm{~mm}$ above the cemento-enamel junction.

The very low scores of the occlusal microleakage observed in this study are in agreement with several other studies, especially with those in which newly developed adhesive systems were used. The proper occlusal seal of both restorative materials, even in thermocycled and loaded groups, indicates that the ormocer Admira and the hybrid composite TPH Spectrum exhibit a good adaptation to sound enamel margins even with a bevel of approximately $0.5 \mathrm{~mm}$. It has been reported that a thin composite material in bevelled occlusal enamel margins could be prone

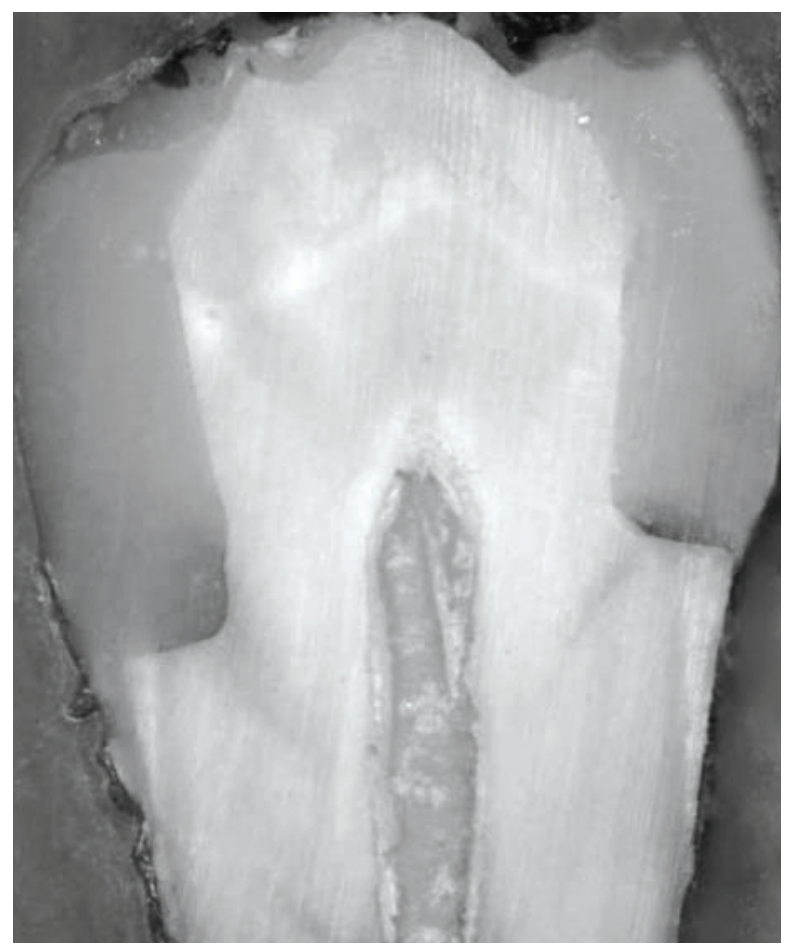

Figure 2. Dye penetration at dentin after thermocycling and loading. 
to fracture by occlusal stresses; 7,32 however in the present study there were no evidence of this kind of composite fracture at the occlusal margins.

In this study, bevels were placed not only on the occlusal margins but also on the approximal buccal and lingual cavity margins. Bevelling along buccal and lingual vertical margins of Class II resin composite restorations was shown to reduce microleakage at the proximo-vertical walls as well as the gingival wall. ${ }^{6,33}$ In the present study, the application of thermo-mechanical loading resulted in high amounts of gingival microleakage in the restorations of both restorative materials. If the bevels had not been placed on the approximal buccal and lingual margins, the gingival microleakage would probably be much more than the scores found in this study.

The findings of high gingival microleakage after the thermo-mechanical load cycling is in agreement with the reports of some previous studies. ${ }^{30-32}$ They indicated that the use of the load cycling combined with thermocycling had an increasing effect on the gingival microleakage when compared to the application of thermocycling or load cycling only. ${ }^{20,27}$ The use of thermomechanical load cycling was also found to be important in other studies with different objectives as for example to evaluate the flexural strength of dental restorative materials. ${ }^{34}$

Some studies showed that in Class II or

Table 1. Frequency of microleakage scores at occlusal and gingival margins in non-thermocycled and non-loaded teeth.

\begin{tabular}{llllll}
\hline Scores & 0 & 1 & 2 & 3 & 4 \\
\hline Occlusal Margins & & & & & 0 \\
Admira & 21 & 1 & 0 & 0 & 0 \\
TPH Spectrum & 21 & 0 & 0 & 1 & 0 \\
\hline Gingival Margins & & & & 1 & 0 \\
Admira & 15 & 6 & 0 & 1 & 0 \\
TPH Spectrum & 16 & 4 & 1 & & \\
\hline
\end{tabular}

Table 2. Frequency of microleakage scores at occlusal and gingival margins in thermocycled and loaded teeth.

\begin{tabular}{|c|c|c|c|c|c|}
\hline Scores & 0 & 1 & 2 & 3 & 4 \\
\hline \multicolumn{6}{|c|}{ Occlusal Margins } \\
\hline Admira & 20 & 2 & 0 & 0 & 0 \\
\hline TPH Spectrum & 20 & 0 & 0 & 1 & 1 \\
\hline \multicolumn{6}{|c|}{ Gingival Margins } \\
\hline Admira & 7 & 6 & 2 & 4 & 3 \\
\hline TPH Spectrum & 10 & 0 & 1 & 3 & 8 \\
\hline
\end{tabular}

Table 3. The mean averages of microleakage scores.

\begin{tabular}{lcccccccc}
\hline & Non-Thermocycled and Non-Loaded & Thermocycled and Loaded \\
\hline Occlusal Margins & A & 0.04 & $\mathrm{a}$ & & & & & \\
Admira & $\mathrm{A}$ & 0.13 & $\mathrm{ab}$ & $\mathrm{A}$ & 0.09 & $\mathrm{a}$ & \\
TPH Spectrum & & & & $\mathrm{A}$ & 0.3 & $\mathrm{a}$ & \\
\hline Gingival Margins & $\mathrm{A}$ & 0.4 & $\mathrm{~b}$ & & & & \\
Admira & $\mathrm{A}$ & 0.4 & $\mathrm{~b}$ & $\mathrm{~B}$ & 1.54 & $\mathrm{~b}$ & \\
TPH Spectrum & $\mathrm{A}$ & $\mathrm{B}$ & 1.95 & $\mathrm{~b}$ & \\
\hline
\end{tabular}

Values labeled with the same character were not significantly different within columns and raws $(P<.05)$. Lower and upper case letters were used for columns and rows, respectively. 
MOD restorations, the adaptation of adhesive materials to the cervical enamel exhibited high performances of marginal seal. ${ }^{7,35}$ These findings could be explained by test methods which did not include the load cycling procedure ${ }^{7}$ or by using different types of restorative materials with different restorative techniques. ${ }^{7,35}$ In a study with Class II cavities, it was reported that Admira exhibited a good marginal integrity at the cervical enamel margins, compared with those of a fine hybrid resin composite. ${ }^{36}$ This assessment may be related to the study design without a thermomechanical load application.

Some past studies pointed out that application of thermocycling (only), significantly increased the microleakage pattern, 18,19,31 while other studies reported that the thermocycling has no effect on microleakage of dental restorations. ${ }^{17,21,23,26,28,30}$ Similar conflicting results regarding the effect of load cycling were found in several investigations and some of them stated that the use of the load cycling procedure did not have an increasing effect on the microleakage, ${ }^{15,19,21,22,26,30}$ as other authors indicated that the application of load cycling (only) had a significant effect on the microleakage of adhesive restorations. . $4,16,20,22,31,37$ These conflicting statements in the evaluation of the effects of thermocycling and load cycling procedures might be related to the variety of the tested materials $6,7,9,11,13,19-21,23,24,28,31$ and/or the different cavity designs $6,7,9-11,14,16,19,20,22,37$ and/or the different test methods ${ }^{7,11}, 12,14-16,19-21,24,25,27,29,31,34,37$ and/or the properties of the hard tissues. ${ }^{7,8,10,11}$

Under the conditions of the present study it was shown that the combined use of thermocycling and load cycling was a decisive factor in assessing the gingival microleakage in Class II adhesive restorations.

\section{CONCLUSIONS}

The results of this in vitro study indicate that a gingival microleakage should be kept in mind when the ormocer Admira as well as the hybrid composite TPH Spectrum are intended to be used in Class II adhesive restorations.

Gingival microleakage still remains to be a clinical problem even with newly developed adhesive systems like ormocers. The ormocer system Admira did not show a superior performance in marginal sealing ability than the composite system TPH Spectrum. Therefore the decision on which product to be used must be left to the practitioner.

For future investigations the thermomechanical load cycling is strongly recommended.

\section{REFERENCES}

1. Kidd EA. Microleakage: A review. J Dent 1976;4:199-206.

2. Bergenholtz G, Cox CF, Loesche WJ. Bacterial leakage around dental restorations: Its effect on the dental pulp. $J$ Oral Pathol 1982;11:439-450.

3. Brännström M. The cause of postoperative sensitivity and its prevention. J Endod 1986;12:475-481.

4. Brännström M. Infection beneath composite resin restorations: Can be avoided? Oper Dent 1987;12:158-163.

5. Going RE. Microleakage about dental restorations: A summarizing review. J Am Dent 1972;84:1349-1357.

6. Hilton TJ, Ferracane JL. Cavity preparation factors and microleakage of Class II composite restorations filled at intraoral temperatures. Am J Dent 1998;11:123-130.

7. Beznos C. Microleakage at the cervical margin of composite Class II cavities with different restorative techniques. Oper Dent 2001;26:60-69.

8. Demarco FF, Ramos OL, Mota CS, Formola E, Justino LM. Influence of different restorative techniques on microleakage in Class II cavities with gingival wall in cementum. Oper Dent 2001;26:253-259.

9. Derhami K, Coli P, Brännström M. Microleakage in Class II composite resin restorations. Oper Dent 1995;20:100-105.

10. Ferrari M, Cagidiaco MC, Davidson CL. Resistance of cementum in Class $\mathrm{II}$ and $\mathrm{V}$ cavities to penetration by an adhesive system. Dent Mater 1997;13:157-162.

11. Ferrari M, Mason PN, Fabianelli A, Cagidiaco MC, Kugel G, Davidson $\mathrm{CL}$. Influence of tissue characteristics at margins on leakage of Class II indirect porcelain restorations. Am J Dent 1999; 12:134-142.

12. Hilton TJ, Schwartz RS, Ferracane JL. Microleakage of four Class II resin composite insertion techniques at intraoral temperature. Quintessence Int 1997;28:135-144.

13. Neme AL, Maxson BB, Pink FE, Aksu MN. Microleakage of Class II packable resin composites lined with flowables: An in vitro study. Oper Dent 2002;27:600-605.

14. Abdalla Al, Davidson CL. Effect of mechanical load cycling on the marginal integrity of adhesive Class I resin composite restorations. J Dent 1996;24:87-90.

15. Darbyshire PA, Messer LB, Douglas WH. Microleakage in Class II composite restorations bonded to dentin using thermal and load cycling. J Dent Res 1988;67:585-587. 
16. Davidson CL, Abdalla Al. Effect of occlusal load cycling on the marginal integrity of adhesive Class $\mathrm{V}$ restorations. Am J Dent 1994;7:111-114.

17. Deveaux E, Hildelbert P, Neut C, Romont C. Bacterial microleakage of Cavit, IRM, TERM and Fermit: A 21 day in vitro study. J Endod 1999;25:653-659.

18. Grossman ES, Sparrius 0. Marginal adaptation of composite resin-restored dentinal cavities. J Prosthet Dent 1990;64:519-522.

19. Hakimeh S, Vaidyanathan J, Houpt ML, Vaidyanathan TK, Von Hagen S. Microleakage of compomer Class V restorations: Effect of load cycling, thermal cycling and cavity shape differences. J Prosthet Dent 2000;83:194-203.

20. Jang KT, Chung DH, Shin D, Garcia-Godoy F. Effect of eccentric load cycling on microleakage of Class $V$ flowable and packable composite resin restorations. Oper Dent 2001;26:603-608.

21. Kubo S, Yokota H, Sata Y, Hayashi Y. Microleakage of selfetching primers after thermal and flexural load cycling. Am J Dent 2001;14:163-169.

22. Kubo S, Yokota H, Sata Y, Hayashi Y. The effect of flexural load cycling on the microleakage of cervical resin composites. Oper Dent 2001;25:451-459.

23. Li H, Burrow MF, Tyas MJ. The effect of load cycling on the nanoleakage of dentin bonding systems. Dent Mater 2002;18:111-119

24. Li H, Burrow MF, Tyas MJ. The effect of thermocycling regimens on the nanoleakage of dentin bonding systems. Dent Mater 2002;18:189-196.

25. Mayer T, Eickholz P. Microleakage of temporary restorations after thermocycling and mechanical loading. J Endod 1997;23:320-322.

26. Yamazaki PCV, Bedran-Russo AKB, Pereira PNR, Swift Jr EJ. Microleakage evaluation of a new low-shrinkage composite restorative material. Oper Dent 2006;31:670676.

27. Rigsby DF, Retief DH, Bidez MW, Russell CM. Effect of axial load and temperature cycling on microleakage of resin restorations. Am J Dent 1992;5:155-159.

28. Bagheri M, Ghavamnasiri M. Effect of cavosurface margin configuration of Class $\mathrm{V}$ cavity preparations on microleakage of composite resin restorations. J Contemp Dent Pract 2008;9:122-129.

29. Xalabarde A, Garcia-Godoy F, Boj JR, Canalda C. Microleakage of fissur sealants after occlusal enameloplasty and thermocycling. $J$ Clin Pediatr Dent 1998;22:231-235.

30. Fruits TJ, Knapp JA, Khajotia SS. Microleakage in the proximal walls of direct and indirect posterior resin slot restorations. Oper Dent 2006;31:719-727.
31. Ozel E, Korkmaz Y. Attar N. Influence of location of the gingival margin on the microleakage and internal voids of nanocomposites. J Contemp Dent Pract 2008;9:65-72.

32. Heintze S, Forjanic M, Cavaller A. Microleakage of Class II restorations with different tracers - Comparison with SEM quantitative analysis. $J$ Adhes Dent 2008;10:259-267.

33. Opdam NJ, Roeters JJ, Kuijs R, Burgersdijk RC. Necessity of bevels for box only Class II composite restorations. $J$ Prosthet Dent 1998;80:274-279.

34. Drummond JL, Mahendra SB. Static and cyclic loading of fiber-reinforced dental resin. Dent Mater 2003;19:226-231.

35. Manhart J, Schmidt M, Chen HY, Kunzelman KH, Hickel R. Marginal quality of tooth-coloured restorations in Class II cavities after artificial aging. Oper Dent 2001;26:357-366.

36. Haller B, Schuster P. Randqualität eines ormocers (Admira) und eines Feinhybridkomposits (Arabesk Top) in Klasse-II-Kavitäten. Dtsch Zahnärztl Z 2000;55:331-335.

37. Ausiello P, Davidson CL, Cascone P, Dee Gee AJ, Rengo S. Debonding of adhesively restored deep Class II MOD restorations after functional loading. Am J Dent 1999;12:8488. 